Special Issue of the 6th International Congress \& Exhibition (APMAS2016), Maslak, Istanbul, Turkey, June 1-3, 2016

\title{
Magnetic Material Based on Mixed-Valent Dinuclear Pivalate and Cyanidometalate
}

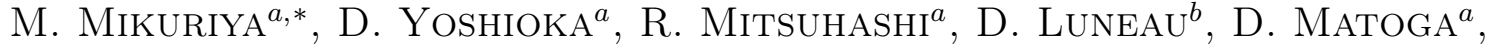 \\ J. SZKLARZEWICZ ${ }^{c}$ AND M. HANDA ${ }^{d}$ \\ ${ }^{a}$ Kwansei Gakuin University, School of Science and Technology, 2-1 Gakuen, Sanda 669-1337, Japan \\ ${ }^{b}$ Laboratoire des Multimatériaux et Interfaces, Université Claude Bernard Lyon 1, \\ Campus de La Doua, 69622 Villeurbanne Cedex, France \\ ${ }^{c}$ Faculty of Chemistry, Jagiellonian University, R. Ingardena 3, 30-060 Krakow, Poland \\ ${ }^{d}$ Shimane University, Interdisciplinary Graduate School of Science and Engineering, \\ 1060 Nishikawatsu, Matsue 669-8504, Japan
}

\begin{abstract}
Mixed-metal complex consisting of ruthenium(II,III) pivalate, $\left(\left[\mathrm{Ru}_{2}(\mathrm{piv})_{4}\right]^{+}\right)(\mathrm{Hpiv}=$ pivalic acid $)$, tetraethylammonium and octacyanidotungstate $(\mathrm{V})$ ions, $\left(\mathrm{Et}_{4} \mathrm{~N}\right)\left[\left\{\mathrm{Ru}_{2}(\mathrm{piv})_{4}\right\}_{2} \mathrm{~W}(\mathrm{CN})_{8}\right] \cdot 4 \mathrm{H}_{2} \mathrm{O}$, was synthesized and characterized by elemental analysis, infrared and UV-vis spectra and temperature dependence of magnetic susceptibilities $(2-300 \mathrm{~K})$. The magnetic susceptibilities, zero-field-cooled and field-cooled magnetizations, and AC susceptibility data showed that the present complex is ferrimagnetic with $T_{c}$ value of $80 \mathrm{~K}$. The field dependence of magnetization exhibited a hysteresis with a coercive field of 17000 Oe at $5 \mathrm{~K}$.
\end{abstract}

DOI: 10.12693 /APhysPolA.131.120

PACS/topics: 75.30.Et

\section{Introduction}

Lantern-type metal carboxylates such as copper(II) acetate have attracted much attention for the past six decades because of their dinuclear core made up by four carboxylate-bridges and unique properties $[1,2]$. In case of ruthenium, mixed-valent dinuclear ruthenium(II)ruthenium(III) state is stable and the $\mathrm{Ru}^{\mathrm{II}} \mathrm{Ru}^{\mathrm{III}}$ carboxylates, $\left[\mathrm{Ru}_{2}\left(\mathrm{O}_{2} \mathrm{CR}\right)_{4}\right]^{+}$, afford a $3 / 2$ spin system $[1,3-$ 5]. This $3 / 2$ spin system can be considered as a good spin source for molecular magnetic materials [526]. In order to understand the magnetic properties of these compounds, systematic investigations were needed for mixed-metal complexes based on dinuclear ruthenium carboxylates and cyanidometalate ions. Recently, we reported on magnetic properties of mixedmetal complexes of dinuclear ruthenium(II,III) carboxylates with dicyanidoargentate $(\mathrm{I}) \mathrm{Ag}(\mathrm{CN})_{2}^{-}$[23], tetracyanidonickelate(II) $\mathrm{Ni}(\mathrm{CN})_{4}^{2-}$ [24], and tetracyanidoplatinate(II) $\mathrm{Pt}(\mathrm{CN})_{4}^{2-}[25,26]$ and hexacyanidocobaltate(III) $\mathrm{Co}(\mathrm{CN})_{6}^{3-}[17]$. These compounds showed a weak antiferromagnetic interaction between $3 / 2$ spins of dinuclear ruthenium units through the cyanidometalate groups. On the other hand, mixed-metal systems with hexacyanidoferrate(III) $\mathrm{Fe}(\mathrm{CN})_{6}^{3-}[17-20]$, hexacyanidochromate(III) [19, 20] and octacyanidotungstate $(\mathrm{V}) \mathrm{W}(\mathrm{CN})_{8}^{3-}[21,22]$ show a ferrimagnetic behavior. It should be noticeable that mixed-metal complex $\left[\left\{\mathrm{Ru}_{2}(\mathrm{piv})_{4}\right\}_{3}\left(\mathrm{H}_{2} \mathrm{O}\right) \mathrm{W}(\mathrm{CN})_{8}\right]$ of ruthenium pi-

*corresponding author; e-mail: junpei@kwansei.ac.jp valate $\left[\mathrm{Ru}_{2}(\text { piv })_{4}\right]^{+}(\mathrm{H}$-piv $=$ pivalic acid $)$ with octacyanidotungstate $\left[\mathrm{W}(\mathrm{CN})_{8}\right]^{3-}$ has a high $T_{c}$ value of $44 \mathrm{~K}$, whereas an analogous mixed-metal complex $\left(\mathrm{PPh}_{4}\right)_{2}\left[\mathrm{Ru}_{2}(\text { piv })_{4} \mathrm{~W}(\mathrm{CN})_{8}\right]$ with octacyanidotungstate and tetraphenylphosphonium ion did not show a ferrimagnetic behavior [22]. In this regard, the presence of tetraphenylphosphonium cation may be a key factor determining the magnetic properties in the mixed-metal systems. In this study, we synthesized new mixed-metal complex of ruthenium(II)-ruthenium(III) pivalate and octacyanidotungstate as shown in Fig. 1 by using tetraethylammonium ion $\left(\mathrm{Et}_{4} \mathrm{~N}^{+}\right)$as a cation in the hope of obtaining new magnetic materials. The isolated mixedmetal complex $\left(\mathrm{Et}_{4} \mathrm{~N}\right)\left[\left\{\mathrm{Ru}_{2}(\mathrm{piv})_{4}\right\}_{2} \mathrm{~W}(\mathrm{CN})_{8}\right] \cdot 4 \mathrm{H}_{2} \mathrm{O}(\mathbf{1})$ was characterized by using elemental analysis, infrared and UV-vis spectroscopies, and temperature dependence of magnetic susceptibilities.

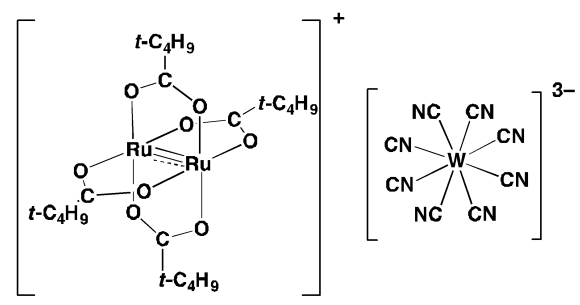

Fig. 1. Chemical structures of $\left[\mathrm{Ru}_{2}(\mathrm{piv})_{4}\right]^{+}$(left) and $\left[\mathrm{W}(\mathrm{CN})_{8}\right]^{3-}$ (right).

\section{Experimental details 2.1. Materials}

Tetrafluoroborate of dinuclear ruthenium(II,III) and potassium octacyanidotungstate(IV) were prepared by a 
method described in the literature $[11,22]$. All of other reagents were commercially available and used as received.

\subsection{Synthesis of $\left(E t_{4} N\right)\left[\left\{R u_{2}(\text { piv })_{4}\right\}_{2} W(C N)_{8}\right] \cdot 4 H_{2} \mathrm{O}$}

To an aqueous solution $(7 \mathrm{ml})$ of $\mathrm{K}_{4} \mathrm{~W}(\mathrm{CN})_{8} \cdot 2 \mathrm{H}_{2} \mathrm{O}$ (21 $\mathrm{mg}, 0.036 \mathrm{mmol})$, an aqueous solution $(7 \mathrm{ml})$ of $\left[\mathrm{Ru}_{2}(\text { piv })_{4}\left(\mathrm{H}_{2} \mathrm{O}\right)_{2}\right] \mathrm{BF}_{4}(30 \mathrm{mg}, 0.23 \mathrm{mmol})$ and aqueous solution $(7 \mathrm{ml})$ of $\mathrm{Et}_{4} \mathrm{NCl}(36 \mathrm{mg}, 0.05 \mathrm{mmol})$ were added. The reaction mixture was stirred overnight in the dark, the resulting brown precipitate was filtered off, washed with water and dried in vacuum. Yield, $22.3 \mathrm{mg}(52 \%)$. Analytically found: C, $37.43 ; \mathrm{H}, 5.50 ; \mathrm{N}$, 6.21\%. Calculated for $\mathrm{C}_{30} \mathrm{H}_{44} \mathrm{~N}_{2} \mathrm{O}_{8} \mathrm{Ru}_{2} \mathrm{~W}: \mathrm{C}, 37.21 ; \mathrm{H}$, $5.58 ; \mathrm{N}, 6.97 \%$. IR $\left(\mathrm{KBr}, \mathrm{cm}^{-1}\right): 1581\left(\nu_{a s} \mathrm{COO}\right), 1417$ $\left(\nu_{s} \mathrm{COO}\right)$. Diffuse reflectance spectra: $\lambda_{\max } 273,437,574$, and $1026 \mathrm{~nm}$.

\subsection{Characterization}

Infrared spectra were recorded on a JASCO MFT-2000 spectrometer as a $\mathrm{KBr}$ pellet. Solid-state UV-Vis spectra were recorded in the range of $200-2000 \mathrm{~nm}$ on a Shimadzu UV-3100 spectrophotometer (reflection method). Elemental analyses were performed on a Thermo Finnigan FLASH EA1112 analyzer. DC and AC magnetic data were measured using a Quantum Design MPMS XL SQUID magnetometer. The magnetic measurements were carried out at University Claude Bernard Lyon 1 on polycrystalline samples. To avoid orientation in the magnetic field, the samples were pressed in a home-made Teflon sample holder equipped with a piston. The data were corrected for diamagnetism of the sample holder and the constituent atoms using Pascal's constants [27].

\section{Results and discussion}

Elemental analysis of the isolated complex showed the 1:2:1 $\left(\mathrm{Et}_{4} \mathrm{~N}: \mathrm{Ru}_{2}(\mathrm{piv})_{4}: \mathrm{W}(\mathrm{CN})_{8}\right)$ formulation $\left(\mathrm{Et}_{4} \mathrm{~N}\right)\left[\left\{\mathrm{Ru}_{2}(\mathrm{piv})_{4}\right\}_{2} \mathrm{~W}(\mathrm{CN})_{8}\right] \cdot 4 \mathrm{H}_{2} \mathrm{O}(\mathbf{1})$ IR data showed a strong $\nu(\mathrm{CN})$ band of $\mathrm{W}(\mathrm{CN})_{8}^{5-}$ moiety at $2146 \mathrm{~cm}^{-1}$ and two COO stretching bands at 1487 and $1420 \mathrm{~cm}^{-1}$ with the difference in energy characteristic of syn-syn bridging carboxylate [28].

As shown in Fig. 2, the diffuse reflectance spectrum of 1 showed a broad band at $1026 \mathrm{~nm}$ in the near-infrared region. The band can be assigned to the $\delta\left(\mathrm{Ru}_{2}\right) \rightarrow$ $\delta^{*}\left(\mathrm{Ru}_{2}\right)$ transition band and showed a red shift compa-

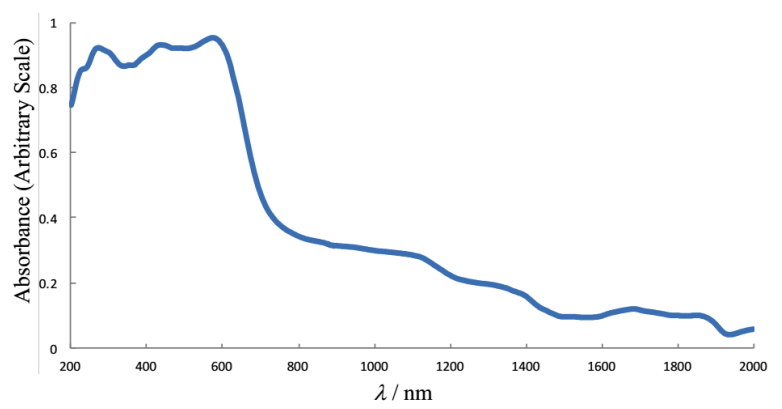

Fig. 2. Diffused reflectance spectra of $\mathbf{1}$

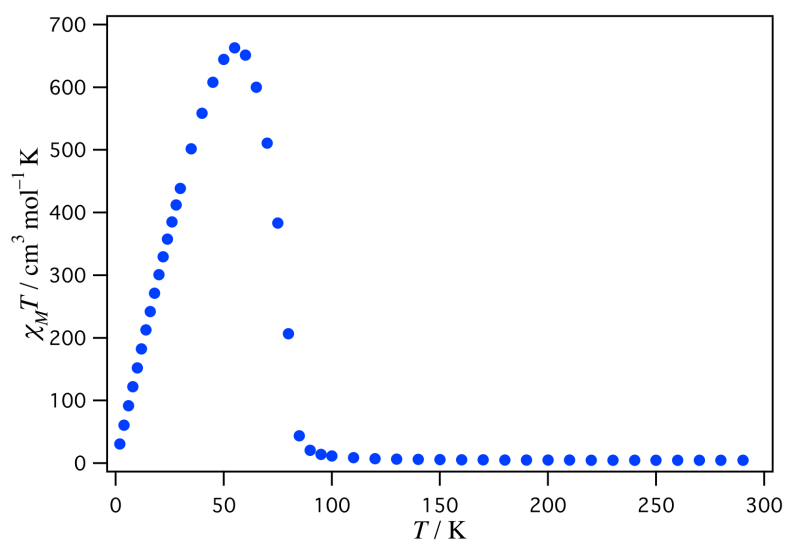

Fig. 3. Temperature dependence of $\chi_{M} T$ of $\mathbf{1}$.

red with that of $\left[\mathrm{Ru}_{2}(\mathrm{piv})_{4}\left(\mathrm{H}_{2} \mathrm{O}\right)_{2}\right] \mathrm{BF}_{4}(990 \mathrm{~nm})$, suggesting the axial coordination of the cyanide group of $\mathrm{W}(\mathrm{CN})_{8}^{3-}$ moiety.

Magnetic susceptibility measurements were made in the temperature range of $2-300 \mathrm{~K}$. The magnetic data of 1 are shown in Fig. 3 in the form of $\chi_{M} T$ plots, where $\chi_{M}$ is the molar magnetic susceptibility per $\left(\mathrm{Ru}_{2}\right)_{2} \mathrm{~W}$ unit. As shown in Fig. $3, \chi_{M} T$ at $300 \mathrm{~K}$ is $4.67 \mathrm{~cm}^{3} \mathrm{~K} \mathrm{~mol}^{-1}$ corresponding to the effective magnetic moment of $6.11 \mu_{\mathrm{B}}$, which is comparable to that expected for magnetically isolated two dinuclear $\mathrm{Ru}_{2}^{\mathrm{II}, \mathrm{III}} S=3 / 2$ ions and a $\mathrm{W}^{\mathrm{V}} S=1 / 2$ ion (theoretical value for $g=2$ ). As the temperature is lowered, $\chi_{M} T$ decreases down to a minimum value of $4.62 \mathrm{~cm}^{3} \mathrm{~K} \mathrm{~mol}^{-1}$ at $250 \mathrm{~K}$ then below it gradually increases until $95 \mathrm{~K}$, then more rapidly up to a maximum of $663 \mathrm{~cm}^{3} \mathrm{~K} \mathrm{~mol}^{-1}\left(72.8 \mu_{\mathrm{B}}\right)$ at $55 \mathrm{~K}$ and then decreases gradually down to $15.3 \mathrm{~cm}^{3} \mathrm{~K} \mathrm{~mol}^{-1}$ $\left(11.1 \mu_{\mathrm{B}}\right)$ at $2 \mathrm{~K}$. The magnetic behavior is characteristic of ferrimagnetic behavior due to antiferromagnetic interaction between $\mathrm{Ru}_{2}^{\mathrm{II}, \mathrm{III}}$ and $\mathrm{W}^{\mathrm{V}}$ ions through the cyanide bridges.
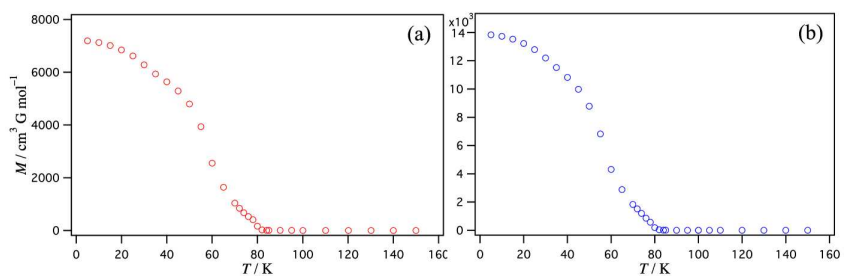

Fig. 4. ZFC (a) and FC (b) magnetization curves measured in $27 \mathrm{G}$ for $\mathbf{1}$.

The zero-field-cooled (ZFC) and field-cooled (FC) magnetizations, $M(T)_{Z F C}$ and $M(T)_{F C}$, respectively, rise below $80 \mathrm{~K}$ (Fig. 4), indicative of $T_{c}$ at $80 \mathrm{~K}$.

Magnetic ordering at $80 \mathrm{~K}$ was confirmed from the presence of peaks in both the real $\left(\chi_{M}^{\prime}\right)$ and imaginary $\left(\chi_{M}^{\prime \prime}\right)$ parts of $\mathrm{AC}$ susceptibility (Fig. 5). This temperature is definitely higher than that of $\left[\left\{\mathrm{Ru}_{2}(\mathrm{piv})_{4}\right\}_{3}\left(\mathrm{H}_{2} \mathrm{O}\right) \mathrm{W}(\mathrm{CN})_{8}\right] \quad\left(T_{c}=\right.$ $44 \mathrm{~K},[22])$ and those found in the analogous complexes of ruthenium carboxylates with hexacyanidometalates $\left[\left\{\mathrm{Ru}_{2}\left(\mathrm{CH}_{3} \mathrm{CO}_{2}\right)_{4}\right\}_{3} \mathrm{M}(\mathrm{CN})_{6}\right]_{n} \quad\left(\mathrm{M}=\mathrm{Fe} \quad\left(T_{c}=\right.\right.$ 


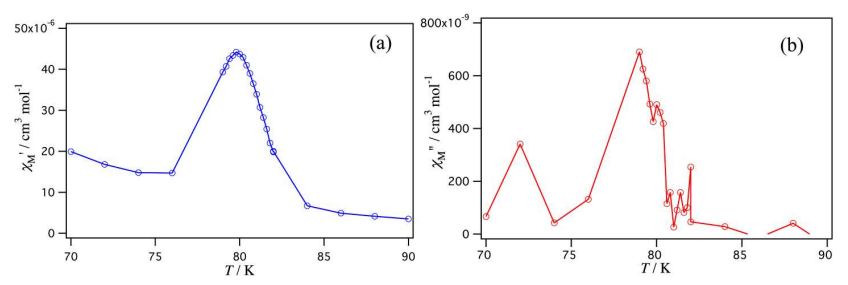

Fig. 5. Real part $\chi_{M}^{\prime}(T)$ (a) and imaginary part $\chi_{M}^{\prime \prime}(T)(\mathrm{b})$ of AC susceptibility data for $\mathbf{1}$.

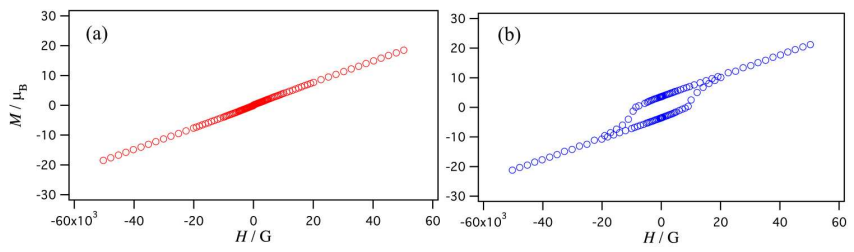

Fig. 6. Magnetic hysteresis loops at $80 \mathrm{~K}$ (a) and $5 \mathrm{~K}$ (b) for 1 .

$2.1 \mathrm{~K},[18]), \mathrm{Cr}\left(T_{c}=33,34.5 \mathrm{~K},[18]\right), \operatorname{Mn}\left(T_{c}=\right.$ $9.6 \mathrm{~K},[18])) ;\left[\left\{\mathrm{Ru}_{2}(\mathrm{piv})_{4}\right\}_{3} \mathrm{M}(\mathrm{CN})_{6}\right]_{n} \cdot 2 n \mathrm{H}_{2} \mathrm{O} \quad(\mathrm{M}=\mathrm{Fe}$ $\left(T_{c}=4.8 \mathrm{~K},[19]\right)$, Cr $\left.\left(T_{c}=37.5 \mathrm{~K},[19]\right)\right)$. It seems that the $\mathrm{Ru}_{2}$ carboxylate and octacyanidotungstate systems have more advantage for attaining the high $T_{c}$ value than the $R u_{2}$ carboxylate systems with the firsttransition-metal cyanides.

Below $T_{c}$, the field dependence of the magnetization, $M(H)$, exhibits hysteresis (Fig. 6). The hysteresis curves at different temperatures show that the coercive field increases as the temperature decreases as expected for a magnet. The coercive field is 17000 Oe at $5 \mathrm{~K}$. The large coercivity may be related with the $2 \mathrm{D}$ layer structure and the large anisotropies of the diruthenium cations and tungstate ions similarly to the case for $\left[\left\{\mathrm{Ru}_{2}(\mathrm{piv})_{4}\right\}_{3}\left(\mathrm{H}_{2} \mathrm{O}\right) \mathrm{W}(\mathrm{CN})_{8}\right]$. Such 2D motif can be hold for the present case, because we found a 2D sheet structure in the similar 2:1 mixed-metal complex, $\left[\left\{\mathrm{Ru}_{2}\left(\mathrm{CH}_{3} \mathrm{COO}\right)_{4}\right\}_{2} \mathrm{Pt}(\mathrm{CN})_{4}\right] \cdot 2 \mathrm{H}_{2} \mathrm{O}$ [26]. The high $T_{c}$ and the large coercive field values can be ascribed to the introduction of the large diffusion of the $5 d$ magnetic orbitals to the metal-metal bonding in the ruthenium carboxylate clusters.

\section{Conclusion}

A new mixed-metal complex was synthesized by introducing the cation, tetraethylammonium ion. The isolated mixed-metal system showed a ferrimagnetic behavior and the $T_{c}$ value was estimated to be of $80 \mathrm{~K}$ from the ZFC and FC studies and AC susceptibility measurements. The mixed-metal systems containing ruthenium carboxylate and octacyanidotungstate are promising for constructing new magnetic materials.

\section{Acknowledgments}

The present work was partially supported by Grant-inAid for Scientific Research No. 26410080 from the Ministry of Education, Culture, Sports, Science and Technology (MEXT, Japan) and the NEXT-Supported Program for the Strategic Research Foundation at Private Universities, 2010-2014.

\section{References}

[1] F.A. Cotton, C.A. Murillo, R.A. Walton, Multiple Bonds between Metal Atoms, 3rd ed., Springer Science and Business Media, New York 2005.

[2] M. Mikuriya, Bull. Jpn. Soc. Coord. Chem. 52, 17 (2008).

[3] M.A.S. Aquino, Coord. Chem. Rev. 248, 1025 (2004).

[4] M.A.S. Aquino, Coord. Chem. Rev. 170, 141 (1998).

[5] M. Mikuriya, D. Yoshioka, M. Handa, Coord. Chem. Rev. 250, 2194 (2006).

[6] Y. Sayama, M. Handa, M. Mikuriya, R. Nukada, I. Hiromitsu, K. Kasuga, in: Coordination Chemistry at the Turn of the Century, Eds. G. Ondrejovic, A. Sirota, Slovak Technical University Press, Bratislava 1999, p. 447.

[7] H. Ishida, M. Handa, M. Mikuriya, X-ray Struct. Anal. Online 30, 9 (2014).

[8] Y. Hiraoka, T. Ikeue, H. Sakiyama, F. Guegan, D. Luneau, B. Gillon, I. Hiromitsu, D. Yoshioka, M. Mikuriya, Y. Kataoka, M. Handa, Dalton Trans. 44, 13439 (2015).

[9] H. Ishida, M. Handa, I. Hiromitsu, M. Mikuriya, Chem. J. Moldova 4, 90 (2009).

[10] H. Ishida, M. Handa, T. Ikeue, J. Taguchi, M. Mikuriya, Chem. Papers 64, 767 (2010).

[11] Y. Sayama, M. Handa, M. Mikuriya, I. Hiromitsu, K. Kasuga, Bull. Chem. Soc. Jpn. 73, 2499 (2000).

[12] D. Yoshioka, M. Mikuriya, M. Handa, Bull Chem. Soc. Jpn. 77, 2205 (2004).

[13] H. Ishida, M. Handa, I. Hiromitsu, M. Mikuriya, Chem. Papers 67, 743 (2013).

[14] M. Handa, H. Ishida, K. Ito, T. Adachi, T. Ikeue, I. Hiromitsu, M. Mikuriya, K. Kasuga, Chem. Papers 62, 410 (2008).

[15] D. Yoshioka, M. Handa, M. Mikuriya, I. Hiromitsu, K. Kasuga, Mater. Sci. Poland 23, 765 (2005).

[16] D. Yoshioka, M. Handa, M. Mikuriya, K. Kasuga, in: Advances in Coordination, Bioinorganic and Inorganic Chemistry, Eds. M. Melnik, J. Sima, M. Tatarko, Slovak Technical University Press, Bratislava 2005, p. 218.

[17] D. Yoshioka, M. Mikuriya, M. Handa, Chem. Lett. 31, 1044 (2002).

[18] T.E. Vos, Y. Liao, W.W. Shum, J.-H. Her, P.W. Stephens, W.M. Reiff, J.S. Miller, J. Am. Chem. Soc. 126, 11630 (2004).

[19] T.E. Vos, J.S. Miller, Angew. Chem. Int. Ed. 44, 2416 (2005)

[20] J.S. Miller, Dalton Trans. 35, 2742 (2006).

[21] D. Matoga, M. Mikuriya, M. Handa, J. Szklarzewicz, Chem. Lett. 34, 1550 (2005).

[22] M. Mikuriya, D. Yoshioka, A. Borta, D. Luneau, D. Matoga, J. Szklarzewicz, M. Handa, New J. Chem. 35, 1226 (2011).

[23] M. Mikuriya, Y. Tanaka, D. Yoshioka, M. Handa, J. Supercond. Nov. Magn. 28, 1013 (2015). 
[24] M. Mikuriya, Y. Tanaka, D. Yoshioka, M. Handa, Chem. J. Moldova 9, 93 (2014).

[25] M. Mikuriya, K. Ono, S. Kawauchi, D. Yoshioka, R. Mitsuhashi, M. Handa, Chem. J. Moldova 10, 48 (2015).

[26] M. Mikuriya, S. Kawauchi, K. Ono, R. Mitsuhashi, N. Yoshinari, T. Konno, H. Tanaka, M. Handa, J. Supercond. Nov. Magn., 1 (2016).
[27] O. Kahn, Molecular Magnetism, VCH, New York 1993.

[28] K. Nakamoto, Infrared and Raman Spectra of Inorganic and Coordination Compounds, Part B: Application in Coordination, Oragnometallic, and Bioinorganic Chemistry, 6th ed., Wiley, New York 2009. 